\title{
Avaliação da Silagem de Diferentes Híbridos de Sorgo (Sorghum bicolor, L. Moench) por meio do Desempenho de Novilhos de Corte Confinados ${ }^{1}$
}

\author{
Mikael Neumann², João Restle ${ }^{3}$, Dari Celestino Alves Filho ${ }^{4}$, Ivan Luiz Brondani ${ }^{5}$, \\ Régis Augusto de Lima Carvalho Bernardes ${ }^{6}$, Alexandre Nunes Motta de Souza ${ }^{7}$, Fernando Kuss ${ }^{8}$
}

RESUMO - Este experimento foi conduzido com o objetivo de estudar os parâmetros relativos ao consumo de alimentos, ganho de peso, conversão alimentar e eficiência energética de novilhos de corte em confinamento, alimentados com quatro dietas contendo silagem de híbridos de sorgo de comportamento agronômico diferenciado: AGX-213 e AG-2002 (forrageiro), AGX-217 e AG-2005E (duplo propósito). Foram utilizados 48 novilhos com idade média de 19 meses e peso médio inicial de $316 \mathrm{~kg}$. A relação volumoso:concentrado foi de 63:37, para todas as dietas testadas. Não houve interação entre fonte de volumoso e período de avaliação em confinamento. A silagem do híbrido AG-2005E propiciou maior consumo de matéria seca e energia digestível, ganho de peso médio diário e melhor conversão alimentar frente aos demais genótipos testados. A análise de contraste mostrou que a inclusão de silagens de sorgo forrageiro (AGX-213 e AG-2002) à dieta alimentar causou redução significativa de 8,84 e 12,11\% no consumo voluntário de matéria seca e energia digestível, respectivamente, frente às silagens de sorgo de duplo propósito (AGX-217 e AG-2005E). Animais alimentados com silagem de sorgo com características de duplo propósito apresentaram maior ganho de peso médio diário $(1,163$ contra $0,943 \mathrm{~kg})$ e foram mais eficientes na transformação de matéria seca e energia digestível consumida em ganho de peso vivo (PV) (7,65 contra 8,73 kg de MS/kg de PV e 19,76 contra $21,84 \mathrm{Mcal} / \mathrm{kg}$ de PV).

Palavras-chave: consumo alimentar, conversão alimentar, eficiência energética, ganho de peso

\section{Feedlot Performance of Steers Fed with Silages of Different Sorghum Hybrids (Sorghum bicolor, L. Moench)}

\begin{abstract}
The experiment was conducted to evaluate the parameters of dry matter intake, weight gain, feed conversion and energy efficiency of feedlot steers, fed with four diets that included silage of hybrids of sorghum with different agricultural behavior: AGX-213 and AG-2002 (forage), AGX-217 and AG-2005E (double purpose). Forty-eight steers with an average age of 19 months and average live weight of $316 \mathrm{~kg}$, were used. The roughage:concentrate ratio was $63: 37$, for all the diets tested. No significant interaction was observed between roughage source and feedlot evaluation period. The sorghum silage of hybrid AG-2005E caused higher dry matter intake, digestible energy intake, daily weight gain and better feed conversion and energy efficiency than the other genotypes. The contrast analysis showed that the silage of the forage hybrids (AGX-213 and AG-2002) caused a significant reduction of the daily voluntary dry matter intake (8.84\%) and digestible energy intake (12.11\%) in comparison to the silage of the double purpose hybrids (AGX-217 and AG-2005E). Steers fed with silage of the double purpose hybrids showed higher daily weight gain ( $1.163 \mathrm{vs} .943 \mathrm{~kg})$ and were more efficient $(\mathrm{P}<.05)$ in converting dry matter intake and digestible energy intake into weight gain (7.65 vs $8.73 \mathrm{~kg}$ of DM/kg LW and $19.76 \mathrm{vs} 21.84 \mathrm{Mcal} / \mathrm{kg} \mathrm{LW}$ ).
\end{abstract}

Key Words: daily weight gain, dry matter intake, energy efficiency, feed conversion

\section{Introdução}

A produção de silagem de alta qualidade é um aspecto que vem sendo trabalhado no setor pecuário, com o objetivo de diminuir os custos de produção. Essa prática proporciona redução significativa na utilização de concentrados (BRONDANI e ALVES
FILHO, 1998; RESTLE et al., 1999a). Silagens de elevado potencial para desempenho animal são obtidas de híbridos de sorgo selecionados por características que confiram elevada concentração de energia na massa das plantas, estabilidade de índices de produtividade e de produção de grãos.

ZAGO (1991), analisando a estrutura física da

\footnotetext{
1 Parte da Dissertação de Mestrado do primeiro autor. Pesquisa parcialmente financiada pela FAPERGS.

2 Eng $-A g r$, MSc. E.mail: mikaelneumann@hotmail.com

3 Eng -Agr, Ph.D., Pesquisador do CNPq, Professor Titular do Departamento de Zootecnia da UFSM - Campus Camobi, 97119-900, Santa Maria - RS. E.mail: jorestle@ccr.ufsm.br

4 Eng -Agr , MSc., Professor do Departamento de Zootecnia da UFSM. E.mail: dcafilho@ccr.ufsm.br

5 Zootecnista, MSc., Professor do Departamento de Zootecnia da UFSM. E.mail: brondani@ccr.ufsm.br

6 Zootecnista, MSc., Professor do Departamento de Zootecnia da UFSM. E.mail: racber@ccr.ufsm.br

7 Bolsista PIBIC-CNPq, Aluno do curso de Medicina Veterinária da UFSM.

8 Bolsista IC-FAPERGS, Aluno do curso de Zootecnia da UFSM.
} 
planta de sorgo, constatou que as porcentagens de colmo e de panícula são características agronômicas que consistentemente se correlacionam com os parâmetros de qualidade, como digestibilidade da matéria seca (MS) e fibra em detergente ácido (FDA) com o ganho de peso médio diário e consumo de matéria seca. O mesmo autor infere que híbridos de sorgo colhidos com teores de matéria seca abaixo de $30 \%$ impedem a produção de silagens de melhor valor nutritivo, devido a perdas durante o processo de ensilagem, contribuindo para um menor consumo voluntário pelos animais, indicando que a seleção e utilização de híbridos de sorgo de colmo seco contornaria este problema. ELIZALDE (1995) considera que a avaliação do valor nutritivo da silagem é melhor interpretada pela resposta do consumo voluntário, digestibilidade e eficiência da utilização de nutrientes digeridos.

VAN SOEST (1994) afirmou que existe correlação negativa entre a porção de fibra em detergente neutro (FDN) e consumo de matéria seca. BORGES et al. (1999) ressaltaram que silagens originárias de híbridos de sorgo com menor teor de FDN apresentaram tendência de maiores taxas de consumo voluntário, desde que não existam outros fatores envolvidos. Segundo JUNG (1989), dentre as frações fibrosas da planta, o componente lignina é considerado indigestível e pode limitar a extensão da digestão, dependendo da sua concentração e composição estrutural.

Conforme ZAGO (1991) e SILVA et al. (1999b), os programas de melhoramento de sorgo forrageiro devem orientar-se, entre outros aspectos, no sentido de determinar características herdáveis na planta, que estejam relacionadas com um processo de fermentação adequada, assim como com a digestibilidade, consumo de forragem e desempenho animal. NUSSIO (1993) retrata em vários estudos que a participação percentual de grãos na matéria seca total não só assegura o maior valor nutritivo original das plantas, mas condiciona a um maior teor de matéria seca à silagem, fato este considerado como o responsável pelo maior consumo dieta alimentar pelos animais. No entanto, sabe-se que a biologia do consumo voluntário e a resposta do desempenho animal é complexa e seus efeitos dependem da interação de fatores relacionados ao animal, alimento e ambiente.

PEREIRA et al. (1993), comparando híbridos de milho e sorgo, evidenciaram similaridades nos parâmetros de produtividade e de valor nutritivo, pois não observaram diferença estatística com relação a produção de matéria seca por unidade de área. Da mesma forma, não observaram diferenças nos coeficientes de digestibilidade in vitro da MS e da matéria orgânica (MO), nos teores de proteína bruta $(\mathrm{PB})$ e respectivos consumos voluntários. No entanto, os dados da literatura demonstram que a silagem de sorgo representa de 70 a $90 \%$ do valor nutritivo da silagem de milho, devido a aspectos relacionados principalmente a grande diversidade genética da cultura do sorgo (ZAGO, 1991). Este fato justifica o estudo das diferentes variedades e/ou híbridos de sorgo presentes no meio técnico.

Entre os numerosos trabalhos de pesquisa realizados com relação a caracterização agronômica produtiva e qualitativa de diferentes híbridos de sorgo para silagem, existe um consenso quanto a necessidade de se estudar a resposta destes diferentes materiais genéticos frente ao consumo de alimentos e o desempenho animal.

Os híbridos de sorgo AG-2002 e AG-2005E encontram-se no mercado há vários anos, enquanto os híbridos AGX-213 e AGX-217 recentemente foram lançados pela empresa de melhoramento para suprir as necessidades dos produtores com relação a materiais com melhores características para produção de silagem de qualidade, visando substituir os materiais mais antigos. Dessa maneira, o objetivo do presente trabalho de pesquisa foi avaliar o efeito de silagens de quatro híbridos de sorgo sobre os parâmetros relativos ao consumo de alimentos, ganho de peso médio diário, conversão alimentar e eficiência energética de novilhos de corte em confinamento.

\section{Material e Métodos}

O experimento foi conduzido no Setor de Bovinocultura de Corte do Departamento de Zootecnia da Universidade Federal de Santa Maria, localizada fisiograficamente na Depressão Central do Estado do Rio Grande do Sul, a uma altitude de $95 \mathrm{~m}$. Cartograficamente, se localiza a $29^{\circ} 43$ ' de latitude Sul e 5342' de longitude Oeste (BRASIL, 1973).

O clima da região é o Cfa (subtropical úmido), conforme classificação de Köppen, com precipitação média anual de $1769 \mathrm{~mm}$, temperatura média anual de $19,2^{\circ} \mathrm{C}$, com média mínima de $9,3^{\circ} \mathrm{C}$ em julho e média máxima de $24,7^{\circ} \mathrm{C}$ em janeiro, insolação de 2212 horas anuais e umidade relativa do ar de $82 \%$ (MORENO, 1961).

Rev. bras. zootec., 30(6S):2099-2109, 2001 
Foram testados quatro tratamentos que corresponderam às dietas alimentares dos novilhos, que incluíram a silagem dos seguintes híbridos de sorgo: $\mathrm{T}_{1}-\mathrm{AGX}-213$ (forrageiro); $\mathrm{T}_{2}-\mathrm{AG}-2002$ (forrageiro); $\mathrm{T}_{3}-\mathrm{AGX}-217$ (duplo propósito); $\mathrm{e}_{4}$ AG-2005E (duplo propósito).

Em uma área de 16 ha, com características de manejo e fertilidade de solo adequadas ao cultivo do sorgo, foram plantados os quatro híbridos a serem avaliados. As lavouras foram implantadas nos dias 21-22/11/1998, em sistema de plantio direto. A plantadeira utilizada foi regulada com espaçamento entre linhas de um metro, profundidade de semeadura de um centímetro e distribuição de 16 a 18 sementes por metro linear. A adubação por ocasião do plantio foi constituída de $300 \mathrm{~kg} / \mathrm{ha}$ de fertilizante NPK, na formulação 10-20-20, e em cobertura 50 dias após o plantio, foram aplicados $150 \mathrm{~kg} / \mathrm{ha}$ de uréia.

As lavouras foram colhidas quando a parte aérea das plantas apresentavam em média de 27\% (AG-2002) a $35 \%(A G-2005 E)$ de matéria seca, com o auxílio de uma ensiladeira regulada com tamanho médio de partícula de 1 a $1,5 \mathrm{~cm}$ e altura de corte média de $20 \mathrm{~cm}$. O material colhido foi armazenado em silos de superfície tipo "torta", compactado com auxílio de um trator, vedados e protegidos com lona plástica de polietileno de três camadas.
A alimentação controlada e a avaliação do desempenho e consumo de alimentos dos animais compreenderam o período de 29 de maio a 16 de agosto de 1999, totalizando 79 dias de confinamento, sendo subdividido em três períodos de avaliação de 21 dias e um quarto período de avaliação com duração de 16 dias.

A dieta alimentar oferecida aos novilhos foi constituída pelas silagens dos quatro híbridos (63\%) e concentrado (37\%), com base na matéria seca. A composição do concentrado encontra-se na Tabela 1.

O sistema de alimentação foi ad libitum, servida duas vezes ao dia, a primeira pela manhã, às $8 \mathrm{~h}$ e a segunda, às $16 \mathrm{~h}$ de cada dia. $\mathrm{O}$ ajuste do fornecimento da quantidade de alimento in natura foi calculado diariamente, considerando uma sobra de $10 \%$ da matéria seca oferecida em relação a consumida, sendo primeiramente distribuído o volumoso no comedouro e sobre o mesmo o concentrado, realizando-se em seguida a mistura. O consumo voluntário dos alimentos foi registrado diariamente por meio da pesagem da quantidade oferecida e das sobras do dia anterior.

As dietas apresentaram na média $11,24 \%$ de proteína bruta, segundo as recomendações do NRC (1984) para a categoria animal utilizada.

O delineamento experimental foi o inteiramente casualizado, composto por quatro tratamentos (silagem

Tabela 1 - Composição percentual dos ingredientes nas dietas experimentais, com base na matéria seca total Table 1 - Composition (\%) of the experimental diets, total dry matter basis

\begin{tabular}{|c|c|c|c|c|}
\hline \multirow[t]{2}{*}{$\begin{array}{l}\text { Constituintes } \\
\text { Components }\end{array}$} & \multicolumn{4}{|c|}{$\begin{array}{l}\text { Fontes de volumoso - Silagem de sorgo } \\
\text { Roughage sources - Sorghum silage }\end{array}$} \\
\hline & AGX-213 & AGX-217 & AG-2002 & AG-2005E \\
\hline Volumoso & 62,66 & 62,60 & 62,95 & 63,06 \\
\hline \multirow{2}{*}{\multicolumn{5}{|c|}{$\begin{array}{l}\text { Roughage } \\
\text { Concentrado }\end{array}$}} \\
\hline & & & & \\
\hline $\begin{array}{l}\text { Casca de soja } \\
\text { Soybean hulls }\end{array}$ & 31,68 & 31,92 & 31,43 & 31,56 \\
\hline $\begin{array}{l}\text { Farelo de soja } \\
\text { Soybean meal }\end{array}$ & 4,45 & 4,49 & 4,42 & 4,44 \\
\hline Uréia & 0,70 & 0,48 & 0,70 & 0,43 \\
\hline $\begin{array}{l}\text { Urea } \\
\text { Sal comum } \\
\text { Salt }\end{array}$ & 0,31 & 0,31 & 0,30 & 0,31 \\
\hline $\begin{array}{l}\text { Salt } \\
\text { Calcário calcítico }\end{array}$ & 0.20 & 0.20 & 020 & ברת \\
\hline Limestone & & & & \\
\hline $\begin{array}{l}\text { Ionóforo* } \\
\text { Ionophore* }\end{array}$ & 0,002 & 0,002 & 0,002 & 0,002 \\
\hline Total & 100,00 & 100,00 & 100,00 & 100,00 \\
\hline
\end{tabular}

* Monensina sódica (Monensin).

Rev. bras. zootec., 30(6S):2099-2109, 2001 
de sorgo AGX-213, AG-2002, AGX-217 e AG-2005E), com três repetições. Cada unidade experimental foi composta por um lote de quatro animais.

Foram utilizados 48 novilhos, das raças Nelore (N), Charolês (C) e suas cruzas, com idade média de 19 meses e peso vivo médio de $316 \mathrm{~kg}$ e escore da condição corporal 3,15, distribuídos em 12 boxes de confinamento com quatro animais cada, equilibrados por peso corporal, escore de condição corporal e grupo genético. Os animais foram submetidos a um período de 15 dias de adaptação às instalações e ao sistema de manejo das dietas experimentais. Neste período, realizou-se a aplicação de um vermífugo de amplo espectro.

Os animais foram pesados, após um jejum de sólidos de 12 horas, no início e no final do período experimental, com pesagens intermediárias correspondentes a cada período de avaliação.

Foram coletadas amostras representativas dos componentes da dieta alimentar no início da adaptação e a cada período de avaliação do experimento. Estas amostras foram pré secadas em estufa de ar forçado a $60^{\circ} \mathrm{C}$ por 72 horas para determinação do teor de matéria seca, sendo seqüencialmente moídas em moinho tipo "Willey" com peneira de malha de um milímetro. Posteriormente, nas amostras de cada alimento foram determinados o teor de matéria seca total (MS), o teor de matéria mineral (MM) por incineração a $550^{\circ} \mathrm{C}$, obtendo-se por diferença o teor de matéria orgânica $(\mathrm{MO}=100-\mathrm{MM})$ e nitrogênio total pelo método micro kjeldahl para obtenção do teor de proteína bruta (PB), conforme AOAC (1984); e a digestibilidade in vitro da matéria orgânica (DIVMO), conforme TILLEY e TERRY (1963). Os teores de fibra em detergente neutro e fibra em detergente ácido pelo método descrito por VAN SOEST e WINE (1967). Para o cálculo de energia digestível (ED), utilizaram-se as equações descritas pelo ARC (1980), com base na digestibilidade in vitro da matéria orgânica (DIVMO) e matéria orgânica (MO). A partir da ED foi calculada a energia metabolizável (EM), multiplicando-se a ED pelo fator 0,82. Para o cálculo da energia líquida de mantença (ELm) e de ganho (ELg) utilizaram-se equações sugeridas pelo NRC (1984).

Os parâmetros estimados foram consumo médio diário de matéria seca (CMS), expresso em $\mathrm{kg}$ / animal (CMSD), por $100 \mathrm{~kg}$ de peso vivo (CMSP) e por unidade de tamanho metabólico (CMSM), bem como o consumo médio diário de energia digestível (CED), expresso em Mcal/animal (CEDD), por 100 $\mathrm{kg}$ de peso vivo (CEDP) e por unidade de tamanho metabólico (CEDM), ganho de peso médio diário (GMD), escore da condição corporal (EC) segundo RESTLE (1972), conversão alimentar (CA) e eficiência energética (CE).

Os dados coletados de cada parâmetro foram submetidos à análise de variância através do pacote estatístico SAS (1993) e as diferenças entre as médias foram analisadas pelo teste de Tukey em nível de significância de $5 \%$.

O modelo estatístico utilizado foi o seguinte: $\mathrm{Y}_{\mathrm{ijk}}=\mu+\mathrm{FV}_{\mathrm{i}}+\mathrm{R}_{\mathrm{j}}(\mathrm{FV})_{\mathrm{i}}+\mathrm{P}_{\mathrm{k}}+(\mathrm{FV} * \mathrm{P})_{\mathrm{ik}}+\mathrm{E}_{\mathrm{ijk}}$ em que: $Y_{i j k}=$ variáveis dependentes; $\mu=$ média das observações; $\mathrm{FV}_{\mathrm{i}}=$ efeito da fonte de volumoso de ordem "i”, sendo 1 (silagem de sorgo AGX-213), 2 (silagem de sorgo AG-2002), 3 (silagem de sorgo AGX-217) e 4 (silagem de sorgo AG-2005E); $\mathrm{R}_{\mathrm{j}}(\mathrm{FV})_{\mathrm{i}}=$ efeito aleatório baseado na repetição dentro do tratamento $\left(\mathrm{FV}_{\mathrm{i}}\right)\left(\right.$ Erro a); $\mathrm{P}_{\mathrm{k}}=$ Efeito do período de avaliação de ordem “ $\mathrm{j}$ ”, sendo 1 (primeiro período), 2 (segundo período), 3 (terceiro período) e 4 (quarto período); $\left(\mathrm{FV}^{*} \mathrm{P}\right)_{\mathrm{ik}}=$ efeito da interação entre o tratamento fonte de volumoso de ordem " $\mathrm{i}$ " $\mathrm{e}$ período de avaliação de ordem " $\mathrm{k}$ "; $\mathrm{E}_{\mathrm{ijk}}=$ erro aleatório residual, assumindo distribuição normal média igual a zero e variância $\sigma^{2}$ (Erro b).

Os dados foram submetidos à análise de regressão polinomial, considerando a variável período (dias), por intermédio do procedimento proc reg do programa SAS (1993).

Comparando a diferença entre as médias dos parâmetros avaliados relativos ao consumo de alimentos e desempenho animal, também realizou-se análise de contraste entre as silagens de híbridos de sorgo forrageiro (AGX-213 e AG-2002) versus sorgo de duplo propósito (AGX-217 e AG-2005E).

\section{Resultados e Discussão}

Constam da Tabela 2 as características das dietas, de acordo com a fonte de volumoso testada.

Analisando os teores de FDN, verifica-se que houve variação de 56,35 a $58,74 \%$ entre as dietas que incluíram silagem de sorgo AG-2005E e AGX-213, respectivamente. Houve pouca diferença no teor de FDN nas dietas, refletindo a variação observada entre as silagens dos híbridos que, também, foi pequena. Para os teores de FDA, estes foram menores para as

Rev. bras. zootec., 30(6S):2099-2109, 2001 
dietas que incluíram silagem de sorgo de duplo propósito (AG-2005E e AGX-217), comparado as que incluíram silagem de sorgo forrageiro (AG-2002 e AGX-213).

Pode-se verificar, na Tabela 2, que a silagem do híbrido AG-2005E proporcionou maior concentração de ED (2,647 Mcal/kg de MS), enquanto o híbrido AG-2002 apresentou a menor concentração de ED (2,469 Mcal/kg de MS). Valores intermediários foram observados para os híbridos AGX-213 (2,538 Mcal/kg de MS) e AGX-217 (2,525 Mcal/kg de MS). Comportamento semelhante, referente à maior concentração de ELg (1,311 Mcal/kg de MS) e ELm (0,738 Mcal/kg de MS), foi observado para dieta alimentar que incluiu silagem de sorgo AG-2005E comparativamente aos demais híbridos testados.

Na Tabela 3 são apresentados os resultados médios de consumo de matéria seca e energia digestível, expressos nas diferentes formas, de acordo com a fonte de volumoso testada. Não houve interação $(\mathrm{P}>0,05)$ entre fonte de volumoso e período de avaliação para CMS e $\mathrm{CED}$, expressos nas diferentes formas.

Os consumos de MS (CMS) e de energia digestível (CED), quando expressos nas diferentes formas (Tabela 3), foram inferiores $(\mathrm{P}<0,05)$ nos animais cuja dieta incluía silagem de sorgo AG-2002, não diferindo $(\mathrm{P}>0,05)$ dadietaqueincluía silagem do AGX-213.
EIFERT (2000), trabalhando com dietas contendo silagem de sorgo AG-2006 associada a diferentes níveis de concentrado, observou que o CMS dos animais em confinamento, aumentou linearmente com o incremento do nível de concentrado. $\mathrm{O}$ autor supra citado justificou, entre outros fatores, que o consumo de alimentos possui estreita relação com a quantidade de matéria seca presente em cada dieta. $\mathrm{O}$ mesmo autor infere que a quantidade de volumoso presente na dieta, associado a maiores conteúdos de água, determina o espaço ocupado no rúmen, podendo vir a limitar o consumo pelo efeito de distensão ruminal. PEREIRA et al. (1993) avaliando diferentes cultivares de sorgo na forma de silagem para alimentação de bovinos de corte, observaram que a silagem do AG2005E promoveu maior CMSD em relação a do AG2002, sugerindo que a diferença foi decorrência do maior conteúdo de MS e a maior proporção de grãos:massa verde, verificada nesta variedade. McDONALD et al. (1991) afirmaram que existe uma estreita relação entre conteúdo de MS da silagem com o consumo voluntário dos animais.

É possível também que o menor CMS das dietas contendo silagem de híbridos forrageiros estejam relacionados à palatabilidade da silagem, visto que apresentaram maiores proporções do componente

Tabela 2- Teores de matéria seca (MS), proteína bruta (PB), fibra em detergente neutro (FDN), hemicelulose (HEM), fibra em detergente ácido (FDA), celulose (CEL), lignina (LIG), energia digestível (ED), energia metabolizável (EM), energia líquida de mantença $(E L m)$ e energia líquida de ganho $(E L g)$ nas dietas experimentais, de acordo com a fonte de volumoso

Table 2 - Average percentages of dry matter (DM), crude protein (CP), neutral detergent fiber (NDF), hemicelulose (HEM), acid detergent fiber (ADF), digestible energy (DE), metabolizable energy (ME), net energy for maintenance (NEm) and net energy for gain (NEg) of the experimental diets, according to roughage source

\begin{tabular}{|c|c|c|c|c|}
\hline \multirow[t]{2}{*}{$\begin{array}{l}\text { Variáveis } \\
\text { Variables }\end{array}$} & \multicolumn{4}{|c|}{$\begin{array}{c}\text { Fonte de volumoso - Silagem de sorgo } \\
\text { Roughage source - Sorghum silage }\end{array}$} \\
\hline & AGX-213 & AG-2002 & AGX-217 & AG-2005E \\
\hline & \multicolumn{4}{|c|}{$\begin{array}{l}\% \mathrm{MS} . \\
\% D M\end{array}$} \\
\hline $\mathrm{MS}(D M)$ & 51,96 & 50,21 & 54,07 & 55,54 \\
\hline $\mathrm{PB}(C P)$ & 10,90 & 11,59 & 11,12 & 11,35 \\
\hline FDN (NDF) & 58,74 & 56,93 & 57,05 & 56,35 \\
\hline HEM (HEM) & 20,27 & 19,48 & 20,23 & 21,86 \\
\hline $\mathrm{FDA}(A D F)$ & 38,47 & 37,45 & 36,82 & 34,49 \\
\hline CEL (CEL) & 32,87 & 31,62 & 32,02 & 30,13 \\
\hline \multirow[t]{2}{*}{$\operatorname{LIG}(L I G)$} & 3,74 & 3,92 & 3,27 & 2,93 \\
\hline & \multicolumn{4}{|c|}{$\begin{array}{c}\text {........ Mcal } / \mathrm{kg} \text { de MS } \\
\text { Mcal/kg of DM }\end{array}$} \\
\hline $\mathrm{ED}(D E)$ & 2,538 & 2,469 & 2,525 & 2,647 \\
\hline $\mathrm{EM}(M E)$ & 2,081 & 2,024 & 2,070 & 2,170 \\
\hline $\operatorname{ELm}(N E m)$ & 1,228 & 1,175 & 1,218 & 1,311 \\
\hline $\operatorname{ELg}(N E g)$ & 0,662 & 0,613 & 0,653 & 0,738 \\
\hline
\end{tabular}

Rev. bras. zootec., 30(6S):2099-2109, 2001 
Tabela 3 - Consumo médio diário de matéria seca (CMS) e energia digestível (CED), expresso por kg/animal e Mcal/animal (CMSD e CEDD), por $100 \mathrm{~kg}$ de peso vivo (CMSP e CEDP) e por unidade de peso metabólico (CMSM e CEDM), de novilhos confinados, de acordo com a fonte de volumoso

Table 3 - Average daily dry matter intake (DMI) and digestible energy intake (DEI), per animal (DMID and DEID), per $100 \mathrm{~kg}$ of live weight (DMIP and DEIP), per unit of metabolic weight (DMIM and DEIM), of feedlot finished steers, according to roughage source

Fonte de volumoso

Consumo diário de matéria seca (CMS)

Roughage source

Daily dry matter intake (DMI)

\begin{tabular}{lccc}
\cline { 2 - 4 } & CMSD $(\mathrm{kg})$ & CMSP $(\% \mathrm{PV})$ & CMSM $\left(\mathrm{g} / \mathrm{kg}^{0}, 75\right)$ \\
& $D M I D$ & $D M I P$ & $D M I M$ \\
\hline AGX-213 & $7,970^{\mathrm{ab}}$ & $2,24^{\mathrm{ab}}$ & $97,37^{\mathrm{ab}}$ \\
AG-2002 & $7,609^{\mathrm{b}}$ & $2,14^{\mathrm{b}}$ & $92,95^{\mathrm{b}}$ \\
Média (forrageiro) & $7,789^{\mathrm{B}}$ & $2,19^{\mathrm{B}}$ & $95,16^{\mathrm{B}}$ \\
Mean (forage) & & & \\
AGX-217 & & $2,36^{\mathrm{a}}$ & $102,92^{\mathrm{a}}$ \\
AG-2005E & $8,522^{\mathrm{a}}$ & $2,33^{\mathrm{a}}$ & $101,86^{\mathrm{a}}$ \\
Média (duplo propósito) & $8,565^{\mathrm{a}}$ & $2,35^{\mathrm{A}}$ & $102,39^{\mathrm{A}}$ \\
Mean (double purpose) & $8,544^{\mathrm{A}}$ & &
\end{tabular}

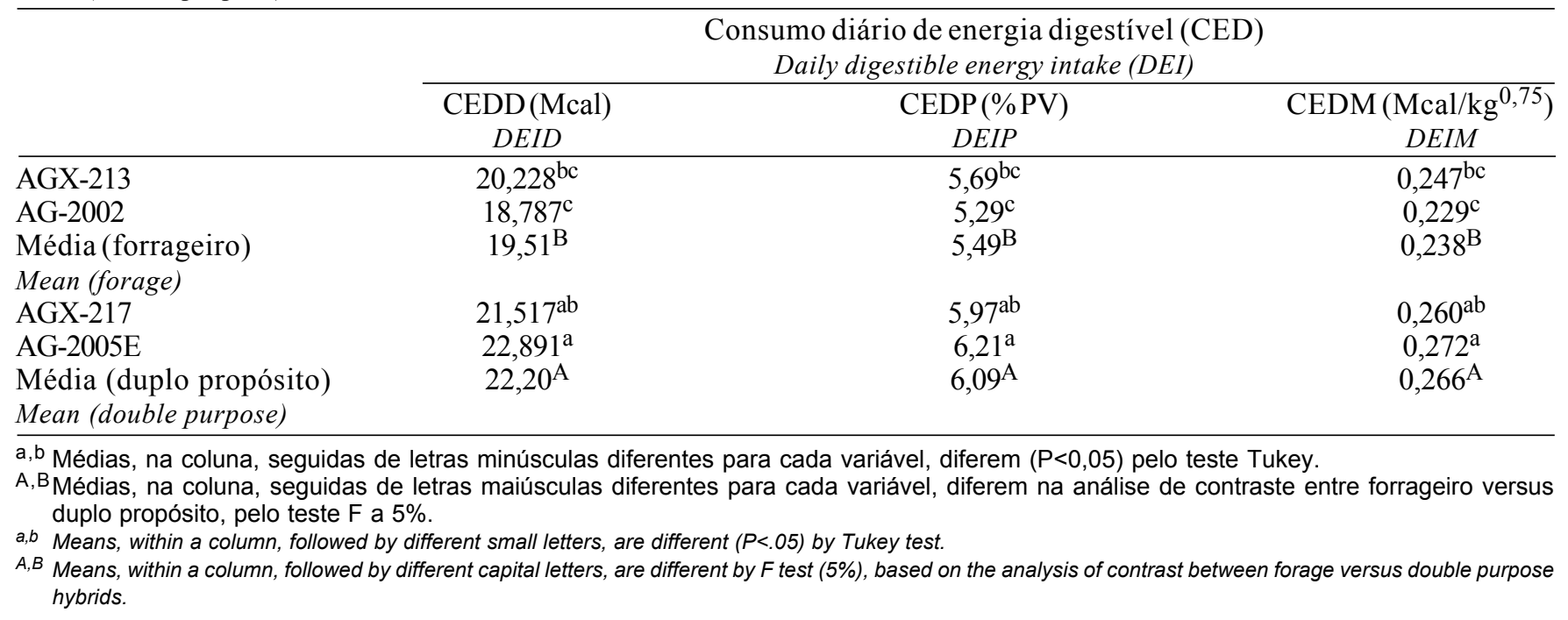

colmo na massa ensilada, comparativamente aos híbridos de duplo propósito, com maior proporção do componente panícula. Vários autores (VAN SOEST, 1994; SILVA, 1999; EIFERT, 2000) relataram que o CMSD também é influenciado pela concentração de FDN dos alimentos. RESTLE et al. (2000), utilizando palha de soja em substituição a silagem de sorgo do híbrido AG-2002 na alimentação de terneiros de corte confinados, verificaram que o aumento no nível de palha de soja causou a diminuição do CMS, atribuindo tal fato ao elevado teor de fibra e baixa digestibilidade da palha.

O CMS médio quando expresso em porcentagem de peso vivo (CMSP) foi semelhante aos encontrados por SILVA et al. (1999a), que observaram valores médios de 2,30 e 2,33\% para novilhos Nelore e de 2,13 e 2,17\% para novilhos F1 Pardo Suíço x Nelore, cuja dieta incluía como volumoso a silagem de sorgo AG-2002 ou BR-303, respectivamente, na relação volumoso:concentrado de 70:30. Já SILVA (1999) utilizando silagem de sorgo AG-2002 e AG-2006 em dietas com relação volumoso:concentrado de 65:35 observou CMSP de 2,52 e 2,65\%, respectivamente, sendo superiores ao do presente experimento.

Verifica-se que o CMS e CED, quando expressos nas diferentes formas, foram inferiores $(\mathrm{P}<0,05)$ nos animais cuja dieta incluía silagem de sorgo forrageiro (AGX-213 e AG-2002). Isto sugere que o CMS e o CED foi limitado por distensão ruminal, em função da maior presença de umidade nestes volumosos, apesar de ser pequena a diferença nos teores de FDN, FDA e DIVMS. BEZERRA et al. (1993), trabalhando com silagem de milho, milho associado com sorgo e rebrotas de sorgo, sugeriram que menores teores de matéria seca (com relação aos adequados para uma silagem) podem limitar o consumo voluntário, da mesma forma que uma proporção elevada de grãos (panícula), em relação à

Rev. bras. zootec., 30(6S):2099-2109, 2001 
planta inteira das rebrotas, possam ter contribuído para melhor consumo dessas silagens.

A tendência de menor consumo das dietas contendo silagem dos híbridos forrageiros pode ser atribuída ao maior teor de FDA e especialmente lignina (Tabela 2), em comparação à silagem dos híbridos de duplo propósito. SPADOTTO et al. (1996) fizeram ponderações similares a respeito da influência negativa dos teores de FDA e lignina da silagem sobre o consumo de MS, quando compararam variedades de milho forrageiro e granífero. WOODY et al. (1983), avaliando as características qualitativas da silagem de milho, observaram alta correlação negativa entre os teores de lignina e FDA da silagem com o CMSD. SILVA et al. (1991), utilizando silagem de sorgo AG2002 e AG-2005E na alimentação de novilhos confinados, verificaram menor CMSD para dieta que incluía o AG-2002 (6,4 vs 7,8 kg/dia).

$\mathrm{Na}$ média geral do CMSD as estimativas foram semelhantes aos consumos relatados por THIAGO et al. (1995), RESTLE et al. (1996) e VARGAS JR et al. (1998). Porém, os CMSD foram inferiores aos valores relatados por FERREIRA et al. (1995), que encontraram consumos de 10,4 e 10,6 kg/dia, com dietas contendo silagem de sorgo granífero e de duplo propósito, respectivamente, bem como aos relatados por SILVA et al. (1999a) com consumos na ordem de 9,38 e $9,9 \mathrm{~kg} /$ dia utilizando dietas com silagem de sorgo AG2006 (duplo propósito) e BR-303 (granífero), na relação volumoso:concentrado de 65:35, respectivamente.

Os CMSD, CMSP e CMSM também foram afetados pelo período de avaliação $(\mathrm{P}<0,05)$, mostrando um comportamento linear frente aos períodos. De acordo com a equação de regressão $\mathrm{Y}=7,5581+$ 0,0119D $\left(\mathrm{R}^{2}=0,2202 ; \mathrm{CV}=6,10 \% ; \mathrm{P}<0,0008\right)$, o CMSD apresentou um incremento de $11,9 \mathrm{~g}$ a cada dia (D) com avanço do período dos animais em confinamento, enquanto que o CMSP e CMSM decresceram, $\mathrm{Y}=2,4367-0,0033 \mathrm{D}\left(\mathrm{R}^{2}=0,3018\right.$; $\mathrm{CV}=4,90 \% ; \mathrm{P}<0,0001)$ e $\mathrm{Y}=102,4166-0,0711 \mathrm{D}$ $\left(\mathrm{R}^{2}=0,0894 ; \mathrm{CV}=5,12 \% ; \mathrm{P}<0,0389\right)$, respectivamente. O CMSD nos períodos de avaliação foram de 7,$81 ; 8,07 ; 8,24$; e $8,54 \mathrm{~kg}$, respectivamente, no primeiro, segundo, terceiro e quarto períodos. MERTENS (1994) relata que o CMSD aumenta com o desenvolvimento corporal dos animais e que esta variação de consumo pode ser melhor expressa como uma taxa do consumo em relação ao peso do animal.

Para o CMSP e CMSM, respectivamente, observaram-se valores de 2,37 e 101,08; 2,29 e 99,41; 2,22 e 97,42 ; e $2,19 \%$ e $97,19 \mathrm{~g} / \mathrm{kg}^{0,75}$, para o primeiro, segundo, terceiro e quarto período. Do início ao final do período de 79 dias de confinamento, o CMSD se elevou em 9,24\%, concordando com ponderações feitas por MERTENS (1994) e VALADARES FILHO et al. (1997), sobre comportamento de ingestão de alimentos dos ruminantes durante seu desenvolvimento corporal. Já para o CMSP e CMSM, observouse redução de 7,59 e 3,86\%, respectivamente.

Os menores consumos de energia digestível da silagem de sorgo AG-2002 e AGX-213 são explicados pela associação dos fatores concentração energética das fontes de volumoso (Tabela 2) e nível de CMS pelos animais (Tabela 3). Animais que tiveram incluído à dieta a silagem de híbridos de sorgo AG-2005E e AGX-217, apresentaram maiores CEDD $(\mathrm{P}<0,05)$, devido a maior concentração de grãos na massa ensilada, o que conferiu maior digestibilidade e aproveitamento dos nutrientes ingeridos. SILVA (1999) verificou CEDD de 26,98 e 32,00 Mcal/dia e CEDP de 7,29 e 8,50\%, na comparação entre silagem de sorgo AG-2002 e AG-2006, respectivamente. O autor justifica esta diferença encontrada de $12,6 \%$ no CEDD, devido ao maior teor de energia presente na silagem do híbrido AG-2006 em relação ao AG-2002 (3,082 vs 2,597 Mcal $/ \mathrm{kg}$ de MS). FREITAS et al. (1994) verificaram CEDD em novilhos cruzas de $18,97 \mathrm{Mcal} / \mathrm{dia}$, enquanto MOLETTA e RESTLE (1992) encontraram consumos para novilhos de diferentes grupos genéticos na faixa de $17 \mathrm{Mcal} /$ dia. O consumo médio de energia digestível, quando expresso em porcentagem de peso vivo (CEDP), foi inferior aos relatados por FLORES (1997), avaliando diferentes grupos genéticos de bovinos, onde encontrou valores entre 6,7 e 7,4\%, assim como aos relatados por QUADROS (1994).

$\mathrm{Na}$ análise dos períodos de confinamento, observou-se um comportamento linear para o CEDD, CEDP e CEDM. As equações de regressão mostraram que o CEDD aumentou com a duração em dias (D) do confinamento dos animais $\left(Y=19,1436+0,0334 \mathrm{D} ; \mathrm{R}^{2}\right.$ $=0,1555 ; \mathrm{CV}=8,33 \% ; \mathrm{P}<0,0056)$. Porém, quando o CED foi expresso por porcentagem de peso vivo e por unidade de tamanho metabólico ( $\mathrm{Y}=6,1806$ - 0,0076D; $\mathrm{R}^{2}=0,1612 ; \mathrm{CV}=6,70 \% ; \mathrm{P}<0,0047$ e $\mathrm{Y}=0,2597-$ $0,00015 \mathrm{D} ; \mathrm{R}^{2}=0,0333 ; \mathrm{CV}=7,05 \% ; \mathrm{P}<0,2143$, respectivamente), houve uma queda no consumo de energia digestível frente aos períodos. Analisando a duração do período de confinamento dos animais, observou-se que o CEDD aumentou em 10,34\%, enquanto

Rev. bras. zootec., 30(6S):2099-2109, 2001 
que o CEDP e o CEDM reduziram na proporção de 7,01 e $2,72 \%$, respectivamente.

Na Tabela 4 são apresentados os valores médios encontrados para as variáveis ganho de peso médio diário (GMD), conversão alimentar (CA) e eficiência energética (CE), conforme a fonte de volumoso testada. Não foi observado interação $(\mathrm{P}>0,05)$ entre fonte de volumoso e período de avaliação do confinamento para as variáveis GMD, CA e CE.

$\mathrm{Na}$ avaliação do desempenho animal, a silagem de sorgo AG-2005E promoveu maior ganho de peso dos animais $(1,281 \mathrm{~kg} /$ dia $)$, não diferindo $(\mathrm{P}>0,05)$ dos híbridos AGX-217 (1,044 kg/dia) e AGX-213 $(0,963 \mathrm{~kg} / \mathrm{dia})$. Os resultados do GMD mostraram que a silagem de sorgo de híbridos de caráter forrageiro (AGX-213 e AG-2002) podem ser utilizadas na formulação de dietas para bovinos em confinamento. No entanto, é necessário aumentar a proporção de concentrado na dieta para proporcionar o mesmo desempenho obtido pela silagem de sorgo dos híbridos de caráter duplo propósito (AGX-217 e AG-2005E). SILVA (1999) não encontrou diferença no GMD (1,044 e 1,194 kg/dia) para dietas contendo silagem de sorgo AG-2002 e AG-2006, respectivamente, na relação volumoso:concentrado de 65:35, embora tenha existido uma diferença numérica de $12,5 \%$ a favor do AG-2006.

$\mathrm{Na}$ análise geral dos períodos de avaliação, o GMD foi menor no segundo período $(0,898 \mathrm{~kg} / \mathrm{dia})$, apresentando um comportamento quadrático $\left(\mathrm{GMD}=1,8392-0,0361 * \mathrm{D}+0,0003 * \mathrm{D}^{2} ; \mathrm{R}^{2}=0,2676\right.$; $\mathrm{CV}=21,4 \% ; \mathrm{P}<0,0009)$, conforme evoluiu o período de avaliação do confinamento.

Não houve diferença $(\mathrm{P}>0,05)$ entre os genótipos testados para os parâmetros conversão alimentar e eficiência energética. No entanto, animais cuja dieta alimentar incluía silagem de sorgo AG-2005E tende$\operatorname{ram}(\mathrm{P}=0,0979)$ a apresentar melhor $\mathrm{CA}(6,88 \mathrm{~kg}$ de $\mathrm{MS} / \mathrm{kg}$ de ganho de peso). Este resultado pode ser explicado pela diferença de ganho de peso que mostrou vantagem para a silagem do híbrido AG-2005E. Já as silagens dos híbridos AGX-213, AG-2002 e AGX-217 proporcionaram uma menor eficiência de transformação do alimento consumido em ganho de peso, com valores de 8,$84 ; 8,61$; e 8,42 , respectivamente. Esperava-se melhor conversão alimentar para os animais que receberam silagem de AGX-213, AG2002 e AGX-217. Porém, os GMD verificados ficaram, na média, abaixo de um quilograma. O maior GMD e a melhor CA apresentados pelos animais alimentados com silagem do híbrido AG-2005E podem ser atribuídos a maior ingestão de grãos na MS da dieta, que foi observado pelo fracionamento das partes constituintes da planta de sorgo $(58,4 \%$ de panícula) e pelo maior valor nutritivo da referida silagem (Tabela 2). Em geral, os resultados do presente trabalho para o parâmetro CA ficaram acima dos relatados por SILVA et al. (1999a), que, traba-

Tabela 4 - Ganho de peso médio diário (GMD), conversão alimentar (CA) e eficiência energética (CE) de novilhos terminados em confinamento, de acordo com a fonte de volumoso

Table 4 - Means for average daily weight gain (ADG), feed conversion (FC) and energy efficiency (EE) for feedlot finished steers, according to roughage source

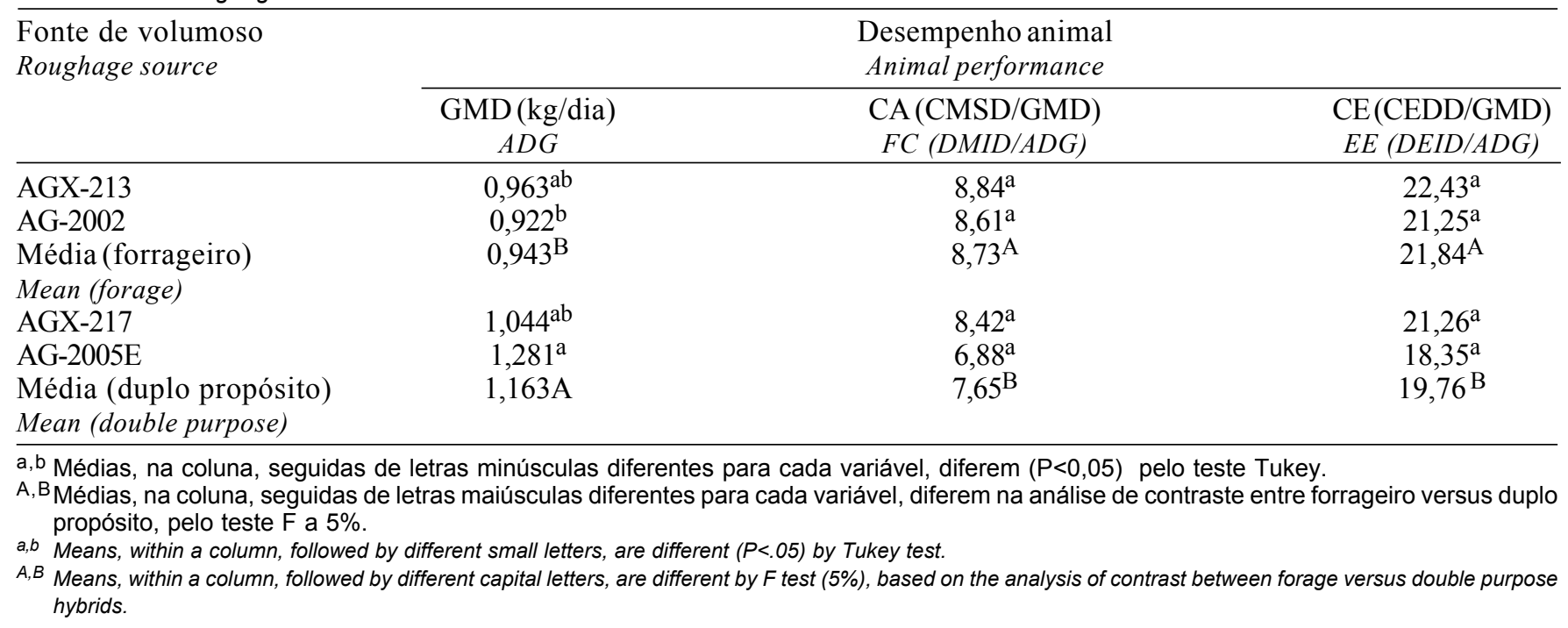

Rev. bras. zootec., 30(6S):2099-2109, 2001 
lhando com dietas contendo silagem de sorgo dos híbridos AG-2002 e BR-303, verificaram uma eficiência alimentar de 7,35 e 7,44 para novilhos Nelore e de 6,53 e 7,23 para novilhos F1 Pardo Suíço x Nelore, respectivamente. Já SILVA (1999), trabalhando com novilhos confinados da mesma categoria e origem do presente trabalho, alimentados com dietas contendo silagem de AG-2002 e AG-2006, observou uma eficiência alimentar de 8,93 e 8,41 , respectivamente, similares às verificadas no presente experimento.

Com relação a $\mathrm{CE}$, a média geral verificada no presente trabalho foi de $20,82 \mathrm{Mcal} / \mathrm{kg}$ de $\mathrm{PV}$, superior a encontrada por RESTLE et al. (1997), que verificaram um consumo médio de $17,3 \mathrm{Mcal} / \mathrm{kg}$ de PV para novilhos Hereford em regime de confinamento recebendo uma dieta com silagem de sorgo na relação volumoso:concentrado média de 55:45. Já RESTLE et al. (1999b), avaliando o desempenho animal em confinamento de novilhos jovens Hereford, $1 / 2$ Jersey $1 / 2$ Hereford e $5 / 8$ Hereford 3/8 Nelore, observaram uma eficiência de transformação média de energia digestível em ganho de peso de 19,84 Mcal/kg de PV, com uma dieta à base de silagem de sorgo, na relação volumoso: concentrado de 46:54.

$\mathrm{Na}$ análise global dos períodos de avaliação, observou-se um comportamento quadrático conforme evoluiu o período para CA $(\mathrm{CA}=1,8075+$ $\left.0,2821 * \mathrm{D}-0,0026 * \mathrm{D}^{2}\right)$ e para $\mathrm{CE}(\mathrm{CE}=4,6635+$ $\left.0,7115^{*} \mathrm{D}-0,0065^{*} \mathrm{D}^{2}\right)$. A resposta obtida está associada a relação entre quantidade de matéria seca consumida e taxa de ganho de peso.

Através da análise de contraste verificou-se que os animais que receberam silagem de sorgo de caráter duplo propósito apresentaram maior $(\mathrm{P}<0,05)$ ganho de peso diário (1,163 vs $0,943 \mathrm{~kg} / \mathrm{dia})$, melhor conversão alimentar (7,65 vs $8,73 \mathrm{~kg}$ de $\mathrm{MS} / \mathrm{kg}$ de ganho de peso vivo) e maior eficiência de transformação de energia em ganho de peso (19,76 vs 21,84 Mcal por kg de MS/kg de ganho de peso vivo). Os híbridos forrageiros (AGX-213 e AG-2002) proporcionaram um GMD 18,92\% inferior à dieta com silagem de híbridos de duplo propósito (AGX-217 e AG-2005E), justificado, certamente, pela menor concentração de ED das dietas que incluíam silagem de híbridos forrageiros. PILLAR et al. (1994) observaram uma diferença de $16,06 \%$ inferior no ganho de peso de terneiros confinados em dietas contendo como volumoso silagem de capim elefante quando comparado a silagem de milho. Já SILVA et al.
(1991), avaliando o desempenho de novilhos Charolês em confinamento com dietas contendo silagem de sorgo forrageiro (AG-2002) ou de duplo propósito (AG-2005E), observaram ganhos de peso de $0,98 \mathrm{e}$ $1,12 \mathrm{~kg} / \mathrm{dia}$ e CA de 6,5 e 6,9 , respectivamente. RESTLE et al. (1996) verificaram maior GMD $(0,75$ vs $0,56 \mathrm{~kg})$ e melhor CA $(8,80$ vs 10,86$)$ na comparação de dietas com relação volumoso:concentrado de $72,5: 27,5$, contendo silagem de milho ou silagem de sorgo forrageiro (AG-2002), respectivamente, justificando os resultados obtidos pelo maior $\operatorname{CMSD}(6,59$ vs $6,00 \mathrm{~kg} / \mathrm{dia}$ ) e ao maior valor nutritivo da silagem de milho frente a silagem de sorgo. No entanto, SILVA et al. (1999a) utilizando dietas contendo silagem dos híbridos de sorgo AG-2006 (duplo propósito) e BR-303 (granífero), na relação volumoso:concentrado 70:30, observaram GMD de 1,329 e 1,200 kg/dia e CA de 6,53 e 7,23 para novilhos cruzados e GMD de 1,043 e 1,014 kg/dia e CA de 7,35 e 7,44 para novilhos Nelore puros, respectivamente.

A condição corporal $(\mathrm{CC})$ no final do período de confinamento, foi afetada $(\mathrm{P}<0,05)$ pela fonte de volumoso, onde animais alimentados com silagem de sorgo AG-2005E apresentaram maior escore $(4,1)$, comparado as dietas com silagem de AG-2002 (3,9), AGX-217 $(3,7)$ e AGX-213 $(3,6)$. O maior consumo de ED dos novilhos que receberam a silagem do híbrido AG-2005E permitiu que os animais depositassem mais gordura, resultando em maior estado corporal. A CC sofreu um incremento linear frente aos períodos, já o ganho em CC apresentou resposta quadrática, aumentando do primeiro ao terceiro período e decrescendo no quarto período. Com relação ao desenvolvimento corporal, este expressou uma resposta linear frente aos períodos, apresentado ao final de 79 dias de confinamento, pesos médios de 389,$8 ; 390,2 ; 400,0$; e 416,3 kg, para os animais alimentados com silagem de sorgo AG-2002, AGX-213, AGX217 e AG-2005E, respectivamente.

\section{Conclusões}

A silagem de sorgo AG-2005E, por apresentar maior qualidade e maior concentração de energia digestível por unidade de matéria seca, proporcionou maior ganho de peso, melhor estado corporal final, melhor eficiência energética e melhor conversão alimentar para terminação de bovinos em confinamento.

A inclusão de silagem de sorgo AG-2002 à dieta de novilhos em confinamento causou redução no

Rev. bras. zootec., 30(6S):2099-2109, 2001 
consumo de matéria seca e no ganho de peso médio diário, aumentando a conversão alimentar.

Em termos de desempenho animal não se verificaram vantagens dos novos materiais AGX-217 e AGX-213 frente aos materiais antigos AG-2005E e AG-2002, respectivamente.

\section{Referências Bibliográficas}

AGRICULTURAL RESEARCH COUNCIL - ARC. 1980. The nutrients requirements of ruminants livestock. Technical review by on Agricultural Research Council Working Party, London. $351 \mathrm{p}$.

ASSOCIATION OF OFFICIAL ANALYTICAL CHEMISTS AOAC. 1984. Official methods of analysis. 14.ed. Washington, D.C. $1141 \mathrm{p}$.

BEZERRA, E.S., TIESENHAUSEN, I.M.E.V.V., OLIVEIRA, A.I.G. et al. 1993. Valor nutricional das silagens de milho, milho associado com sorgo e rebrotas de sorgo. R. Soc. Bras. Zootec., 22(6):1044-1054.

BORGES, A.L.C.C., GONÇALVES, L.C., NOGUEIRA, F.S. 1999. Silagem de sorgo de porte baixo com diferentes teores de tanino e de umidade de colmo. II - Alterações nos carboidratos durante a fermentação. Arq. Bras. Med. Vet. Zootec., 51(5):491-497.

BRASIL. Ministério da Agricultura. 1973. Levantamento de reconhecimento de solos do Rio Grande do Sul. Rio de Janeiro: Departamento Regional de Pesquisa Agropecuária: Divisão de Pesquisas Pedológicas. 431 p. (DNPEA, Boletim Técnico, 30).

BRONDANI, I.L., ALVES FILHO, D.C. 1998. Produção de silagem de qualidade. In: RESTLE, J. et al. (Eds.) Produção intensiva com qualidade em bovinos de corte. Santa Maria: UFSM. p.82-88.

EIFERT, E.C. Silagens de sorgo e de triticale associadas a niveis de concentrado para alimentação de terneiros de corte desmamados precocemente. Santa Maria, RS: UFSM, 2000. 150p. Dissertação (Mestrado em Zootecnia) - Universidade Federal de Santa Maria, 2000.

ELIZALDE, H.F. 1995. El valor nutritivo de los ensilages. R. Arg. Prod. Anim., 15(1):103-121.

FERREIRA, J.J., VIANA, A.C., MIRANDA, J.E.C. et al. 1995. Efeito de silagens de milho, de sorgo e de capim elefante no desempenho de novilhos confinados. Sete Alagoas: EMBRAPA-CNPMS. 16p. (EMBRAPA-CNPMS. Boletim de Pesquisa, 2).

FLORES, J.L.C. Desempenho em confinamento e características de carcaça e da carne de bovinos de diferentes grupos genéticos abatidos aos quatorze meses. Santa Maria: UFSM, 1997, 109p. Dissertação (Mestrado de Zootecnia) - Universidade Federal de Santa Maria, 1997.

FREITAS, J.A., FONTES, C.A.A., SOARES, J.E. et al. Exigências de energia para ganho de peso em bovinos (Zebuínos e mestiços) e Bubalinos. Estudo I. In: REUNIÃO ANUAL DA SOCIEDADE BRASILEIRA DE ZOOTECNIA, 30., Maringá, 1994. Anais... Maringá: SBZ, 1994. p.482.

JUNG, H.G. 1989. Forage lignin and their effects on fiber digestibility. Agron. J., 81(1):33-38.

McDONALD, P., HENDERSON, N., HERON, S. 1991. The biochemistry of silage. 2.ed. Chalcombe publications. 339p.
MERTENS, D.R. Regulation of forage intake. 1994. In: FAHEY JR., G.C. et al. (Eds.) Forage quality, evaluation and utilization. American Society of Agronomy, Crop Science of America, Soil Science of America, Madison, WI. p.450-493.

MolettA, J.L., RESTle, J. 1992. Desempenho em confinamento de novilhos de diferentes grupos genéticos. Ciência Rural, 22(2):227-233.

MORENO, J.A. 1961. Clima do Rio Grande do Sul. Porto Alegre: Secretaria da Agricultura. 41p.

NATIONAL RESEARCH COUNCIL - NRC. 1984. Nutrient requirements of domestic animals. 6.rev.ed. Washington D.C.: National Academy Press.

NUSSIO, L.G. 1993. Milho e sorgo para produção de silagem. In: SANTOS, F.A., NUSSIO, L.G., SILVA, S.C. (Eds.) Volumosos para bovinos. Piracicaba: FEALQ. p.75-177.

PEREIRA, O.G., OBEID, J.A., GOMIDE, J.A. et al. 1993. Produtividade de uma variedade de milho (Zea mays L.) e de três variedades de sorgo (Sorghum bicolor L. Moench) e o valor nutritivo de suas silagens. R. Soc. Bras. Zootec., 22(1):31-38.

PILLAR, R.C., RESTLE, J., SANTOS, G.L. et al. 1994. Silagens de milho (Zea mays, L.) ou capim-elefante (Pennisetum purpureum, Schum.) cv. Napier para alimentação de terneiros de corte confinados. Ciência Rural, 24(2):387-392.

QUADROS, A.R.B. de. Avaliação de duas fontes de proteina na alimentação de bovinos de diferentes idades em regime de confinamento. Santa Maria, RS: UFSM, 1994.122p. Dissertação (Mestrado em Zootecnia) - Universidade Federal de Santa Maria, 1994.

RESTLE, J. Comportamento reprodutivo do rebanho de gado de corte da fazenda experimental de criação experimental agronômica da UFRGS. $1^{\circ}$ Semestre, 1972. Seminário da disciplina de Técnicas de Pesquisa. Curso de Pós-Graduação em Agronomia, UFRGS, 1972.

RESTLE, J., BRONDANI, I.L., ESCOBAR, R.B. et al. Efeito de dietas contendo farelo de arroz integral ou desengordurado, combinado com silagem de milho ou de sorgo forrageiro no desempenho de novilhos. In: REUNIÃO ANUAL DA SOCIEDADE BRASILEIRA DE ZOOTECNIA, 33, Fortaleza, 1996. Anais... Fortaleza: SBZ, 1996. p.108-109.

RESTLE, J., FLORES, J.L.C., VAZ, F.N. et al. 1997. Desempenho em confinamento, do desmame ao abate aos quatorze meses, de bovinos inteiros ou castrados, produzidos por vacas de dois anos. Ciência Rural, 27(4):651-655.

RESTLE, J., BRONDANI, I.L., BERNARDES, R.A.C. 1999a. O novilho super precoce. In: RESTLE, J. (Ed.) Confinamento, pastagens e suplementação para produção de bovinos de corte. Santa Maria: UFSM. p.191-214.

RESTLE, J., BRONDANI, I.L., FLORES, J.L.C. et al. 1999b. Desempenho de genótipos de novilhos para abate aos catorze meses, gerados por fêmeas de dois anos. Pesq. Agropec. Bras., 34(11):2123-2128.

RESTlE, J., ALVES FILHO, D.C., BRONDANI, I.L. et al. 2000. Palha de soja (Glicine max) como substituto parcial da silagem de sorgo forrageiro (Sorghum bicolor L. Moench) na alimentação de terneiros de corte confinados. Ciência Rural, 30(2):319-324.

SAS INSTITUTE. SAS/STAT user's guide: statistics. 4 ed. 1993. 943p. Version 6, Cary, NC. v.2. 1993.

SILVA, L.C.R., RESTLE, J., LUPATINI, G.C. Utilização de diferentes tipos de silagem como fontes de volumoso na terminação de novilhos em confinamento. In: REUNIÃO ANUAL DA SOCIEDADE BRASILEIRA DE ZOOTECNIA, 28., 1991, João Pessoa. Anais... João Pessoa: SBZ, 1991. p.278.

Rev. bras. zootec., 30(6S):2099-2109, 2001 
SILVA, N.L.Q. Terminação de novilhos em confinamento alimentados com silagem de dois híbridos de sorgo (Sorghum bicolor L. Moench) associados a três niveis de concentrado. Santa Maria: UFSM, 1999. 100p. Dissertação (Mestrado de Zootecnia) - Universidade Federal de Santa Maria, 1999.

SILVA, J.M., FEIJÓ, G.L.D., THIAGO, L.R.L.S. et al. 1999a. Desempenho animal e avaliação do potencial produtivo de forragens para ensilagem, por intermédio de diferentes fontes de suplementação nitrogenada. Rev. bras. zootec., 28(3):642-653.

SILVA, F.F., GONÇALVES, L.C., RODRIGUEZ, J.A.S. et al. 1999b. Qualidade de silagens de híbridos de sorgo (Sorghum bicolor (L.) Moench) de portes baixo, médio e alto com diferentes proporções de colmo+folhas/panícula. 2. Avaliação do valor nutritivo. Rev. bras. zootec., 28(1):21-29.

SPADOTTO, A.J., SILVEIRA, A.C., FURLAN, L.R. et al. 1996. Avaliação da silagem de milho das variedades granífera e forrageira no desempenho de bovinos das raças Nelore e Canchim em regime de confinamento. Rev. bras. zootec., 25(1):1-12.

THIAGO, L.R.L.S., EUCLIDES FILHO, K., FIGUEIREDO, G.R. et al. Efeito bioeconômico de níveis de concentrado na engorda de bovinos confinados. In: REUNIÃO ANUAL DA SOCIEDADE BRASILEIRA DE ZOOTECNIA, 32., Brasília, 1995. Anais... Brasília: SBZ, 1995. p.279.

TILLEY, J.M., TERRY, R.A. 1963. A two-stage technique for the in vitro digestion of forage crops. J. Brit. Grassl. Soc., 18:104-111.

VALADARES, R.F.D., GONÇALVES, L.C., RODRIGUEZ, N.M. et al. 1997. Níveis de proteína em dietas de bovinos. 1. Consumo e digestibilidade aparentes totais e parciais. Rev. bras. zootec., 26(6):1252-1258.
VAN SOEST, P.J., WINE, R.H. 1967. Use of detergents in analysis of fibrous feeds. IV. Determinations of plant cellwall constituents. Journal of Association Official Analysis Chemists, 50:50.

VAN SOEST, P.J. 1994. Nutritional ecology of the ruminant. 2.ed. Ithaca: Cornell University Press. 476p.

VARGAS JR., F.M., SANCHEZ, L.M.B., PASCOAL, L.L. et al. Desempenho de terneiros de corte alimentados com diferentes fontes protéicas e com silagem de sorgo colhida a diferentes alturas de corte. In: REUNIÃO ANUAL DA SOCIEDADE BRASILEIRA DE ZOOTECNIA, 34., 1998, Botucatu. Anais... Botucatu: SBZ, 1998. p.558-560.

ZAGO, C.P. 1991. Cultura de sorgo para produção de silagem de alto valor nutritivo. In: PEIXOTO, A.M., MOURA, J.C., FARIA, V.P. (Eds.) Anais do simpósio sobre nutrição de bovinos. 4.ed. Piracicaba: FEALQ. p.169-217.

WOODY, H.D., FOX, D.G., BLACK, J.R. 1983. Predicting net energy value of corn silage varying in grain content. J. Anim. Sci., 57:710-716.

Recebido em: $02 / 04 / 01$ Aceito em: 30/07/01 